PDFlib PLOP: PDF Linearization, Optimization, Protection

Page inserted by evaluation version www.pdflib.com - sales@pdflib.com 


\section{Just a Song? Exploring the Aesthetics of Popular Song Performance}

Would you ask a writer if his book is real or fiction? It's just a song.

\section{P. Diddy (Sean Combs)}

In 1987 when Bruce Springsteen released the album Tunnel of Love with its songs of disillusioned love and estrangement, many fans wondered whether his recent marriage to Julianne Phillips was in trouble. More recently, rapper P. Diddy (Sean Combs) has been asked if his hit song "I Need a Girl (Part 1)" expressed his feelings about the aftermath of his relationship with Jennifer Lopez. ${ }^{1}$ Why do listeners make assumptions about a singer's inner life based on the songs he or she sings? Is it a "folk" version of the expression theory of art? Do we expect emotional authenticity from singers? Springsteen and Combs write their own material and so may be particularly burdened with such expectations. Yet similar expectations about the relationship between performers and songs seem to operate even for singers who do not write their own material. Would we not be disappointed if we learned that Paul Robeson regarded "Go Down, Moses" as just a song, with scant relevance to his own life or to the lives of African-Americans more generally?

In this paper I confront a cluster of questions concerning an issue that genuinely puzzles me. When singers perform, either in front of a live audience or in a recording, what are they doing? Is there anything ontologically distinctive about vocal performance? What expectations do audiences impose on singers and how do these expectations shape vocal performance practices? What relationship do we assume between the performer and that which is conveyed by the song and why do we assume this relationship? That we do make certain assumptions about the relationship between singers and songs is clear, I think, in our expectations and attitudes regarding which songs are appropriate for which singers.

My point of departure (Section I) will be a recent philosophical analysis of musical performance-that of Stan Godlovitch. ${ }^{2}$ Drawing on his account, I discuss some of the expectations I believe that audiences typically have of vocal performance (Section II), and then suggest some answers (none very satisfactory) to the question of what sort of aesthetic activity singing is (Section III). Finally, I offer some tentative answers to why singing arouses special difficulties (Section IV). Briefly, I draw on Susanne Langer's earlier work and argue that our uncertainty about what singing is can be traced back to a more fundamental tension regarding the human voice and the conflicting demands on it to be both a musical instrument and an instrument of self-expression. Although there has been some treatment of singing in the philosophy of music, the topic has failed to attract the interest it deserves. ${ }^{3}$ So part of my task in this paper will be to make the case that singing raises some special issues and is worthy of philosophical attention.

I will concentrate on public performances of song, rather than singing in the shower, along with the car radio, to children at bedtime, and so forth. My focus will be on standards, popular, rock, and folk songs. Besides the songs and singers mentioned in the first paragraph, examples of what I have in mind include Ella Fitzgerald 
singing the songs of Arlen, Porter, and Gershwin; Bob Dylan singing his own compositions, folksongs, and works by others; songs by the Beatles sung by them and by others; and the singers and songs featured on the television program "American Idol." For the sake of keeping the topic manageable (and because I suspect they arouse different kinds of problems) I will exclude choral or ensemble singing (including barbershop quartets and gospel choirs), diegetic songs performed in movies, and songs in music dramas. But I will include these latter songs if they are taken out of their original contexts and made to stand alone. So I mean to include songs such as "Someday My Prince Will Come," "It Never Entered My Mind," "Send in the Clowns," and "Stormy Weather." I will also exclude opera and art song. It seems to me that to be properly appreciated these make different demands on listeners, and audiences impose different expectations on them than they do on the songs I shall be concerned with. (However I cannot defend these claims here.)

Stan Godlovitch offers the most elaborated and cogent philosophical analysis of musical performance of which I am aware. His account is particularly valuable in pointing out some aesthetically significant and rewarding aspects of performance that are too often overlooked. According to Godlovitch, performances are large, complex, integrated events that draw together sounds, agents, works, and listeners. ${ }^{4}$ With further analysis of each of these four components performance emerges as, "a complex activity which co-ordinates and focuses actions, skills, traditions, and works in order to define and create musical experience for the receptive listener." "Godlovitch accords more weight to the performer-listener axis than to the composer-performer relationship. Although performances can fail by misrepresenting works, performers do not have unconditional obligations to composers. However performers do indeed have certain categorical obligations to listeners, and so performances can also fail by disaffecting listeners. ${ }^{6}$

In the course of examining the role of human intentional agency in performance, Godlovitch reflects on a thought experiment. Could a very sophisticated computer simulator be said to give a performance? His answer is no. In coming to this answer Godlovitch identifies and illuminates some of the features audiences find important in performance. To anticipate his conclusions: we expect that musical performances are by persons and to exclude the performer's physical presence and behavior from the aesthetic experience would seem an "unintelligible deprivation."7 Godlovitch writes "We are drawn to personal details, and these seamlessly intertwine with our aesthetic expectations; for example, the riotous life of the performer, his cranky, immature conduct at august gatherings, his wayward attitude to his listeners, his crippling depressions, his bitter envy of his colleagues, his rapt intensity on stage, his savage career ambitions, and the like." 8 Finally, "artist and artwork, performance and performer are quite as inseparable as people are from their histories, external and internal." 9

II

Godlovitch emphasizes instrumental performance because the presence of language and meaning in song would needlessly complicate a general account of musical performance. However, his account, with its stress on the concrete physicality and distinctive personality of the performer, can help us bring out some of the particular difficulties posed by vocal performance. I will argue that we make assumptions about the appropriateness or fit of the relationship between singers and songs that we do not so readily make regarding instrumentalists and their material, and that our expectations regarding which songs are appropriate for which singers go beyond similar expectations for instrumentalists and their repertoires. If these expectations are thwarted or violated, there will be negative consequences for aesthetic experience. This section takes a closer look at the role of audience expectations in structuring the experience of vocal performance. I will begin with a general discussion and attempt further systematization later.

Crucial to my discussion is the notion of a public persona. A singer's public persona is the 
face, body, and personal history he or she presents to the audience. It includes such factors as gender, race, age, and ethnicity, as well as quirks of personality such as those described by Godlovitch. This information is conveyed by the singer's appearance, clothing choices, and the statements and activities reported by the media or circulated among fans. A public persona may transparently reflect a singer's true personality; more likely, it will be highly mediated and constructed. Although an instrumentalist's public persona plays a role in our experience of instrumental performance, a singer's public persona, I will try to show, plays an even greater role in our experience of vocal performance. In particular, it is crucial in shaping our expectations regarding which songs are appropriate for which singers.

'Appropriate' here could be understood in several different ways. I have in mind aesthetic appropriateness as opposed to moral, legal, or practical appropriateness. There may indeed be songs that are not morally appropriate for certain singers, but I want to set aside such questions. Aesthetic appropriateness is not exhausted by considerations of whether a song is suitable to the singer's ability or vocal range, although these considerations certainly do affect it. Probably every musician has certain favorite, especially challenging works that he or she enjoys playing in the privacy of home or for friends but would not dare bring to a stage. Similarly, considerations of aesthetic appropriateness go beyond the question of whether a work is out of step with the singer's established style. Such crossovers are often accepted by audiences and can be aesthetically interesting. ${ }^{10}$

When does a vocal performance fail to be aesthetically appropriate in the sense I am trying to develop? When the public persona of the singer inhibits the successful communication of whatever is crucial in the song such that the audience fails to be convinced. Conviction that this particular singer is appropriate for this song and vice versa is among the necessary conditions of taking routine or standard pleasure in the performance of a song. Such pleasure encompasses (but is not limited to) pleasure in the sonic qualities of the singer's voice, in the way the song is sung, in the interplay between the lyrics and the melody, and in the beauty or expressiveness of the performance. ${ }^{11}$ The notion of conviction I have in mind is not completely rational; songs are not arguments, after all. A successful performance of a song might move an audience in various ways, from delight to sadness to chagrin. Such emotional responses (when befitting the song in question) count as evidence of an audience's having been convinced.

What is communicated or fails to be communicated in a song? Since one thing that sets song apart from other types of music is that singers can convey a text, the answer that may come most readily to mind is "the song's lyrics." Yet I believe that this is correct in fewer instances than one might think. The types of songs under consideration in this paper are what Stephen Davies has called ontologically thin. "Thinner" works determine less of the fine detail of their performance than do thicker ones. ${ }^{12}$ For one thing, songs are a form of oral communication and as such are subject to the burdens and limitations of oral communication. Song texts tend to be redundant and to trade in generally familiar simplifications. ${ }^{13}$ Folksongs (including children's songs, lullabies, ballads, and blues songs) often exist in numerous versions; verses may be dropped or sung in a different sequence. This would seem to indicate that conveying the nuances of a particular text in a fixed order is not necessary. Furthermore, some of the examples I am most interested in are instances of popular art and so, trivially, must be cognitively accessible to their intended audiences. Cognitive accessibility in turn requires some fidelity to familiar forms. ${ }^{14}$

Successful communication of a song cannot, then, be reduced to successful communication of the song's lyrics. Song is music, text is not. Indeed communicating a particular text is not sufficient (and in some instances not necessary) for the communication of a song. Imagine a performance of "Bourgeois Blues" in which the lyrics were perfectly comprehensible but none of the song's emotion was conveyed. I do not think that we would consider this a successful performance. What is in fact crucial for the successful communication of a specific song is likely to depend on that particular song and the performance tradition and audience expectations in which it is embedded. Examples of songs for which the communication of a particular text is important might include many 
of Cole Porter's songs and songs of political protest. In other cases the voice functions more like a musical instrument; what is crucial is the communication of the melody and with it a dominant emotional mood. Examples here include many blues songs and "Guess I'll Hang My Tears Out to Dry." In still other caseslullabies, work songs, marching chants, "It Don't Mean a Thing (If It Ain't Got That Swing)"- - a mood and rhythmic sense are important.

What aspects of a performance can hinder successful communication of a song such that an audience is left unconvinced? Obviously, a poor performance can. Arguably, so, too, would performance choices that are at odds with what the song conveys in a standard or typical performance. Examples might include a syntactically precise but emotionally flat rendition of "Bourgeois Blues" or a loud boisterous performance of a lullaby. However, not every eccentric performance choice leads to failure of audience conviction; a good singer can make seemingly inappropriate decisions with little resulting loss of aesthetic value. For example, Nina Simone's up-tempo, almost chatty rendition of "Mood Indigo" strikes me as aesthetically defensible, as does Barbra Streisand's dirge-like rendition of "Happy Days Are Here Again." Simone and Streisand succeed in highlighting aspects of these songs that are obscured in typical renditions. There can be exhilaration just behind the bluest moods; a silver lining can conceal a cloud. When singing "against" a song in this way is successful, I suspect it is because the aesthetic experience offered is sufficiently rich to provide sustained routine or standard pleasure. Not every questionable or "against the grain" performance choice will be aesthetically successful; some may be interesting enough to provoke a response of "isn't that clever" or "how odd." Although there are elements of pleasure in such reactions, these responses are not reliable or enduring enough to constitute sustained aesthetic payoff. ${ }^{15}$

More important to my concerns in this paper are instances in which the singer's public persona works against what the song conveys, such that audiences fail to be convinced and as a result do not take routine or standard pleasure in the performance. This brings us to considerations of which songs are appropriate for which singers. Some songs are aesthetically appropriate for almost any performer. "Happy Birthday" comes to mind, as do the bulk of standards. But not all songs are appropriate for all singers. Each aspect of a singer's persona can influence which songs an audience would find convincing if he or she decides to sing them. Let us take a closer look at each of these factors in turn.

Some songs are inappropriate for performers above or below certain ages. An incongruity is likely if a young performer sings of weary worldliness ("It Was a Very Good Year," "Thanks for the Memories," "Hum Drum Blues") or if an obviously jaded older performer sings a "youthful" song ("My Heart Belongs to Daddy," "I Feel Pretty").

A performer's gender can affect which songs are aesthetically appropriate for him or her. Theodore Gracyk has argued that the authorship of a song attaches to the gendered body of the singer, regardless of our knowledge of actual authorship. ${ }^{16}$ (Gracyk is primarily interested in rock music, but the point would seem to hold for the wider range of music discussed in this paper.) For example, even if we know that Otis Redding wrote "Respect" and have heard his hit recording, when we hear Aretha Franklin sing it, it becomes difficult not to think of it as a woman's demand for respect from a man. Gracyk's claim strikes me as largely correct: I do not know of any male vocalists who have performed, say, "Natural Woman," nor can I imagine any who could and hope to convince an audience. Yet perhaps gender is not even a necessary condition. "The Girl from Ipanema" has been successfully recorded by both men and women, despite the narrative perspective being male. Nina Simone's rendition of Nat Adderly and Oscar Brown Jr.'s "Work Song" describing life on a chain gang is (to this listener, anyway) no less credible for being sung by a woman, despite the historical fact that there were few women on chain gangs. "Mining for Gold" by the Cowboy Junkies begins with the words "We are miners, hard rock miners." The performance by the female lead vocalist convinces me-it is only after the song finishes that I am reminded that mining is a notoriously male-dominated profession. $^{17}$

I suspect that a performer's gender is salient only in combination with other factors such as race and ethnicity, personality, and age. I do not 
think that just any female vocalist could sing "Work Song" or "Mining for Gold" and convince an audience. (Imagine Brittany Spears, Jennifer Lopez, or Whitney Huston singing these songs.) Simone is able to make us believe in "Work Song" not only because of her musical skill and aesthetic choices, although these are certainly factors.

Race and ethnicity are additional factors that make up what I have called the singer's "public persona" and that influence aesthetic appropriateness and hence audience conviction. To propose what I hope will be two uncontroversial examples, most likely it would not be aesthetically appropriate for a white vocalist to sing either "My skin is black/My arms are long" (from Nina Simone's "Four Women") or "Now I'm mighty like a rose, all dressed up in fancy clothes/I'm just another brown gal that's all full of vim" (from Lil Hardin Armstrong's "Brown Gal"). ${ }^{18}$ I doubt that a white vocalist could convince an audience, and not because of any lack of musical skill on her part. There would be too much incongruity between the lyrics ("My skin is black" or "I'm a brown gal") and the performer's appearance, and the incongruity would distract from anything else. The same incongruity can arise in songs in which the narrative voice is not identified as belonging to a particular race or ethnicity, as it is in these two. Possible examples include "Strange Fruit," and "Go Down, Moses" because of their long association with AfricanAmerican performers, rather than because of any textual content. Audiences who have come to expect African-American vocalists to sing these songs may not be ready to accept them delivered by non-blacks.

In any discussion of performance and race the topic of authenticity is all but unavoidable. In his much discussed paper, "Race, Ethnicity, Expressive Authenticity: Can White People Sing the Blues?" Joel Rudinow characterizes authenticity as the kind of credibility that comes from having the appropriate relationship to an original source. ${ }^{19} \mathrm{He}$ argues that the authenticity of a blues performance turns on the degree of mastery of the idiom rather than on the performer's ethnicity. Evidence of authenticity can be sought "in and around the performance" for the performer's recognition and acknowledgment of indebtedness to sources of inspiration and technique. ${ }^{20}$
An audience's perception of a vocalist's authenticity to a particular tradition would seem to be influenced by the performer's public persona and to involve factors that go beyond those mentioned by Rudinow. This is illustrated in the film 8 Mile starring white rapper Eminem. ${ }^{21}$ The film climaxes with a "battle" (rapping contest) between Jimmy (the character played by Eminem) and a succession of African-American rappers, staged in front of a predominantly African-American audience. Up to this point the film can be seen as an "argument" for the plausibility of Jimmy's victory. It is not just Jimmy's appropriate relationship to original sources that is seen as crucial, although the film takes care to make us aware of it. More importantly, we have seen Jimmy's difficult life, economic deprivation, hassles on the job, difficulty finding love, his pleasure and ability in rapping, and his close friendships with African Americans. In the rap that wins the final contest, Jimmy taunts his AfricanAmerican opponent with lacking authenticity despite being African-American: he comes from a loving suburban middle-class family and has had the advantage of an elite private school education. The extent of a performer's authentic experience is important to the audience judging the rap contest; the implication is that it should be so for us too. Yet it should be said that not every viewer was so convinced; one reviewer charged that "the film embraces the absurdity of a white rapper who takes down a brother in a club full of black people-perhaps more black people than own Eminem records." 22

A vocalist's personality is another factor that influences what kinds of songs an audience will accept from him or her. By personality I have in mind only those aspects of character on public display, and some singers will present to the public a thicker or more vivid personality than others. I have never met Madonna and know nothing of what she may be "really" like. Elements of her public persona however are fairly well established: She presents herself as brash, sexy, driven, difficult, and bluntspeaking. I suspect that these elements of Madonna's public persona would make it difficult to accept her rendition of certain types of songs. For example, her public persona would be at odds with the sorrowful monologues ("Don't Explain," “Ain't Nobody's Business," 
and so on) performed so effectively by Billie Holiday and others. Similarly, Frank Sinatra's public persona as a swaggering hipster makes it difficult for me to take seriously his rendition of the Gershwin classic, "Someone to Watch Over Me." The vulnerability expressed in the song's lyrics seems incongruous with elements of Sinatra's public persona. I can accept Sinatra drinking in a bar after the end of a love affair"One for My Baby (And One for the Road)" but I have trouble believing his self-description as "a little lamb lost in the wood" ("Someone to Watch Over Me"). Whether Sinatra may have experienced such moments of vulnerability is beside the point; his public persona (at least by the middle-to-late period of his career when I saw him perform the song on TV) seemed at odds with them.

No doubt there is a dialectic in effect here: the kinds of songs a singer typically performs also work to influence audience perception of his or her personality. A recent article about music promoter Jason Flom and his struggles in marketing singer Cindy Almouzni (Cherie) illustrates this point nicely. Songwriters were having difficulty creating the right up-tempo number for her because most dance songs are about sex. Flom explained, "Cherie doesn't sing about sex. She sings about love. So we need a dance song about love. [A recent hit with sexually explicit lyrics] is not the right song for Cherie." ${ }^{, 2}$ An appropriate song choice is seen as reflecting the singer's personality, and this in turn is part of the construction of a public persona.

To summarize, audiences accept certain songs from some singers but not from others. If there is too great an incongruity or mismatch between a singer's public persona and what is conveyed in a particular song, audiences will fail to be convinced. They will not accept this song from this singer and so will be inhibited from taking pleasure in the performance. Of the factors that comprise a singer's public persona, race and gender would seem to be most firmly entrenched and difficult to sing against, although we have seen that personality can influence an audience's perception of gender appropriateness.

Could a singer exploit the incongruity between his or her public persona and a particular song? He or she could for the sake of humor, but there are other possibilities. I do not deny that there may be aesthetic payoffs in say, Madonna singing the blues or Bruce Springsteen singing "The Man I Love." Singers may have goals in performance other than convincing an audience. Yet the distancing effect likely to be produced by such performances would work against the experience of routine or standard pleasure.

Before ending my discussion of public persona and audience expectations I need to mention one further complication. So far I have written as though "listeners" and "the audience" are homogenous. No doubt some readers have already suspected that the reality is more complicated; there may be different audiences with different expectations both between genres and within them. The audience for jazz singing is not the same as for pop singing; the audience for Nina Simone is not the same as that for Diana Krall (although in both cases there may be some overlap). Different audiences (and different individual listeners) will have different expectations of singers and different conceptions of authenticity. We saw earlier that not everyone who watched 8 Mile was ready to accept the character played by Eminem as a rapper on par with African Americans. Among listeners, there may be more or less willingness to accept singers as interpreters in their own right. More unsophisticated listeners may have increased difficulty recognizing the possible distance between singer and material.

III

All of this leads to my initial question-Given that there are constraints on the songs we can accept from a singer given his or her public persona, what are singers doing? What sort of an activity is a public performance of a song? One answer can be eliminated immediately: singing a song is not like reading a paper at an academic conference. Although singers convey a text, the text is not necessarily the most important thing they convey. In reading an academic paper, the text is the primary element to be communicated. If Smith is stranded by a snowstorm and cannot get to her session in time, her colleague Jones can read the paper without too much loss, provided Jones is a competent reader. If Smith 
notoriously mumbles or is otherwise difficult to understand, we may be relieved that Jones will read the paper instead (although of course we may like Smith and miss her presence).

Nor is most public singing quite like poetry recitation or public literary readings. In literary readings, as at academic conferences, the communication of the text is crucial. This is not to deny that poets and novelists convey other things beside their texts and that we see them for other reasons than to hear a text. We may watch an author present his or her work in the hope of gaining insight into it or in order to make the name on the cover of the book into a real human being. Still, the communication of a particular text is of primary importance. Poetry texts would seem to be ontologically thicker than song texts. Granted, bizarre effects may result from an inappropriate coupling of poem and reader (say, a child reading a poem clearly meant to be in the voice of a blasé adult). Yet these complications need not detain us as public poetry readings are usually limited to authors reading their own work. Although a poet might read another's work, it is unlikely he or she would devote an entire evening to "cover" poems. In contrast, many great singers perform nothing but songs written by others.

A more promising answer is that some singing is like acting. Within the limits set by his or her public persona, a singer, like an actor, sometimes inhabits a role. An aesthetically successful performance of a song should make us believe (or make-believe) that the singer actually is falling in love ("This Could Be the Start of Something Big"), sad at the end of an affair ("Smoke Gets in Your Eyes"), or contrite and rueful ("You Were Always on My Mind"). Our rational selves know (or should know) that the singer may be none of these things. Indeed, a performer who sang these three songs in succession simply could not go through such a sequence of emotional ups and downs and still complete the songs.

In other ways, singing and acting would seem to be markedly different. If a successful vocal performance was the successful inhabiting of a role, we could accept any song from any singer, just as long as the singer was skilled enough in communicating whatever was crucial for communication of the song. But although skill and aesthetic choice in performance can do much of the work of convincing an audience, they are not in themselves sufficient. If a singer's public persona is too much at odds with what the song conveys, I doubt that any amount of skill or taste can make up for the incongruity. Clearly there are elements of acting in singing - expressing emotion one may not actually feel or adopting the perspective of a song's narrator that may be at odds with one's "true" character. Only the least sophisticated listeners would fail to acknowledge these "deceptive" elements. Yet a singer's acting must not stray too far afield from his or her public persona. Emotion and narrative perspective can be successfully feigned and accepted by audiences; there will be limits to audience acceptance of the performance of gender, age, and race. Although we accept for the most part that actors play at being someone else, we expect singers, at some level, to be themselves, or at least to be true to the persona they have established.

IV

I began this paper by trying to give a general account of the aesthetic appropriateness (or lack thereof) that can obtain between song and singer, depending on the singer's public persona. Drawing on this account, I tried to say something about what sort of an aesthetic activity singing is. Results were only partly satisfactory; the art of singing would seem to share more with theatre than it does with other forms of oral communication such as literary and academic paper readings and poetry recitations. However intuitions pulled in two different directions (as intuitions so often do). If singing shares elements with acting and might be seen as a form of theatre why then can a performer not convince an audience of any song that he or she has the technical skill to sing? Whence comes this tension in singing? Some remarks by Susanne Langer can help here.

In her discussion of musical performance Langer distinguishes between self-expression, such that the work is a vehicle for the performer's moods, and self-expression understood as "ardor for the impact conveyed." 24 This latter form of self-expression is the performer's actual feeling, his or her 
"impassioned utterance" or contagious enthusiasm for the content of the work. This quality, Langer claims, belongs naturally to the human voice. However, the demands placed on the human voice when it is asked to perform in song are in conflict with its function as an instrument of biological response. She writes: "[A]ll actual emotions, crude or fine, deep or casual, are reflected in [the voice's] spontaneously variable tone. It is the prime avenue of self-expression, and in this demonstrative capacity not really a musical instrument at all." 25

The tension in singing, then, reflects the tension between the voice as instrument of self-expression and the voice as musical instrument. In all singing, elements of selfexpression mix with elements of performance and it is difficult to imagine any singing that could be purely one or the other. (Howls of grief and shrieks of joy are not songs, after all.) Recognizing this tension can help account both for the power of some of the best singers and for the lack of aesthetic appropriateness we sense when a singer chooses the wrong song. In some of the most effective and moving vocal performances, the voice as musical instrument overlaps nearly seamlessly with the voice as instrument of self-expression. Critic Alex Ross writes: "Some performers exert such a powerful presence-Billie Holiday, Sinatra, Elvis-that they seem to become the authors of songs that were actually the work of schlumpy men in the Brill Building." 26 I know exactly what he means. Johnny Cash's rendition of the song "I Hung My Head" on his American IV: The Man Comes Around is so authoritative that I have trouble accepting that he did not write it. (Readers will be able to supply their own examples.) When great performers sing the "right" songs there seems to be little gap between the voice as expressive of self and the voice as musical instrument. It is all too easy to believe that the song comes "straight from the heart," although the more sophisticated a listener, the more he or she is likely to be aware that professional singing is not mere self-expression. When singers choose the "wrong" song, the resulting incongruity thwarts our tendency to hear the human voice as a vehicle of self-expression.
$\mathrm{V}$

The questions I posed at the beginning of this paper were: What are singers doing in performance and is vocal performance ontologically distinctive? What kinds of expectations do audiences impose on singers? What is the relationship assumed between the performer and whatever is conveyed by the song and why is this relationship assumed? I am at the point to offer some (tentative) conclusions: in singing a song a singer conveys text (lyrics), melody, and a dominant emotional mood. He or she does so through a public persona, formulated to invite, to control, and to resist audience expectations. As Godlovitch has persuasively argued, a musical performer's concrete physical presence and personality are important to our aesthetic experience of the performance. These factors are even more significant in our aesthetic experience of vocal performance. The audience expects the singer's persona and song to be congruent in ways I have elaborated. If the persona and the song seem incongruous with expectations, then the voice as instrument will work not with but against the voice as embodied. Public singing is a performance-an act-but because it implicates a concrete physical body it will always tend to be heard as self-expressive. As Paul Thom writes, since performing is an activity, the performer's body is "part of the being of the performance" rather than merely part of its cause. ${ }^{27}$ Although pertinent for instrumentalists, his claim would seem to have even greater significance for singers, who are not physically separate from their instruments. When singing is heard as self-expressive, incongruities can arise between the "self" conveyed in the song and the concrete physical presence of the singer. When these incongruities are too unsettling, audiences will fail to be convinced by the performance and will be inhibited from taking pleasure in it.

Singing, even singing as circumscribed for the purposes of this paper, is a philosophically rich and ontologically complex phenomenon. In particular, my account has had little to say about the emotional power of singing and its sources. The distinction I drew between public performances of song and singing in more intimate contexts (to children or along with the car radio) is not as sharp as I have implied. As 
one commentator has written, song plays on my tendency to take it as a message for $m e .^{28}$ This claim needs to be qualified before it is wholly plausible and deserves extended phenomenological analysis. However it strikes me as likely that the intimacy of singing in private contexts spills over into public singing, or that a similar intimacy connects them both.

Much remains to be done, especially on the complications raised by opera, art song, musical theatre, song in film, and ensemble singing. I hope that I have at least begun to ask some important questions about singing and to have shown that it is a rich philosophical topic, deserving further consideration. ${ }^{29}$

\section{JEANETTE BICKNELL}

Department of Philosophy

University of Ottawa

Ottawa, Ontario

Canada

\section{INTERNET: bicknellj@hotmail.com}

1. This question was put to him by (among others) Michael Spector in "I Am Fashion: Guess Who Puff Daddy Wants to Be?" New Yorker, September 9, 2002, hardly an unsophisticated source. Combs's reply provides the epigraph of this paper.

2. Stan Godlovitch, Musical Performance: A Philosophical Study (London: Routledge, 1998).

3. Philosophers who have written on singing include: Theodore Gracyk, Rhythm and Noise: An Aesthetics of Rock (Duke University Press, 1996) and I Wanna Be Me: Rock Music and the Politics of Identity (Temple University Press, 2001); Peter Kivy, Osmin's Rage: Philosophical Reflections on Opera, Drama, and Text (Cornell University Press, 1999); Gary Tomlinson, Metaphysical Song: An Essay on Opera (Princeton University Press, 1999); Jerrold Levinson, "Song and Music Drama," in The Pleasures of Aesthetics: Philosophical Essays (Cornell University Press, 1996), pp. 42-59; Armen T. Marsoobian, "Saying, Singing, or Semiotics: 'Prima la Musica e poi le Parole' Revisited," The Journal of Aesthetics and Art Criticism 54 (1996): 269-277; Joel Rudinow, "Race, Ethnicity, Expressive Authenticity: Can White People Sing the Blues?" The Journal of Aesthetics and Art Criticism 52 (1994): 127-137; Richard Shusterman, "Art Infraction: Goodman, Rap, Pragmatism," Australasian Journal of Philosophy 73 (1995): 269-279; and Francis Sparshott, "Singing and Speaking," The British Journal of Aesthetics 37 (1997): 199-210. Earlier works that address these issues are Susanne Langer, Feeling and Form: A Theory of Art (New York: Scribner, 1953) and Victor Zuckerkandl, Man the Musician, trans. Norbert Gutterman (Princeton University Press, 1976).

4. Godlovitch, Musical Performance, p. 13.

5. Godlovitch, Musical Performance, p. 50.
6. Ibid.

7. Godlovitch, Musical Performance, p. 142.

8. Godlovitch, Musical Performance, p. 139.

9. Godlovitch, Musical Performance, p. 143.

10. I am thinking of examples such as Johnny Cash's rendition of U2's "One," Nick Cave's "The Mercy Seat," and Trent Reznor's "Hurt," Tom Jones's cover of Prince's electro-funk "Kiss," and Run DMC's rap over Aerosmith's "Walk This Way."

11. I have resorted to the odd locution of "routine" or "standard" pleasure to distinguish the type of pleasure usually evoked by a vocal performance from pleasure (1) that does not depend on vocal performance, such as pleasure in a singer's physical appearance or (2) that is evoked by the irony or incongruity of performance choices. I cannot consider ironic vocal performances here because any elucidation of irony in music would have to be situated in an account of irony more generally, and so is beyond the scope of the present paper.

12. See Stephen Davies, Musical Works and Performances: A Philosophical Exploration (Oxford: Clarendon Press, 2001), pp. 3-4. I leave further discussion of the ontological status and identity conditions of songs for another time.

13. For more on the nature of song verse and its relation to poetry, see the masterful study by Mark W. Booth, The Experience of Songs (Yale University Press, 1981), especially pp. $1-28$.

14. See Gracyk, I Wanna Be Me, pp. 18-26.

15. Could an ironic performance ever provide a sufficiently sustained response to constitute the kind of rich aesthetic experience I have in mind? Although I cannot rule out this possibility, I doubt it. However, I cannot provide arguments here.

16. Gracyk, I Wanna Be Me, p. 181.

17. I am less sure about Gracyk's claim (I Wanna Be Me, p. 209) that "destabilization of gender" occurs when masculine discourse is delivered in a female's voice, especially when the song in question has already been popularized by and strongly identified with male performers. Given the short memory of the pop music audience, listeners may not even be aware that their current favorite (sung by a woman) is a cover version rather than an original (sung by a man).

18. Nina Simone, "Four Women," from the album Let It All Out, Phillips PHS 600202 originally recorded September 30 or October 1, 1965 in New York; Lil Hardin Armstrong, "Brown Gal," originally recorded October 27, 1936. Lyrics transcribed from Lil Hardin Armstrong and Her Swing Orchestra, 1936-1940, Chronological Classics Volume 564 and downloaded from <http:// www.heptune.com/lyrics/browngal.html $>$ on December 6, 2004.

19. Rudinow, "Race, Ethnicity, Expressive Authenticity," p. 129.

20. Rudinow, "Race, Ethnicity, Expressive Authenticity," p. 135.

21. I set aside the question of whether rapping is singing or something else.

22. See Elvis Mitchell's, "White Hot: From Rap to Riches," review of 8 Mile (Universal Pictures), New York Times, November 8, 2002.

23. John Seabrook, "The Money Note," New Yorker, July 7, 2003, p. 53

24. Langer, Feeling and Form, p. 141. 
25. Ibid.

26. Alex Ross, "Rock 101," New Yorker, July 14, July 21, 2003.

27. Paul Thom, For An Audience: A Philosophy of the Performing Arts (Temple University Press, 1993), p. 14.

28. Booth, The Experience of Songs, p. 14 (emphasis in original).

29. For discussion and comments on earlier drafts, I am grateful to Lee Brown, John Carvalho, Stephen Davies,
Susan Feagin, Theodore Gracyk, Ian Jarvie, Jerrold Levinson, Roberta Morris, Chris Tucker, William Webster, Nancy Zeligman, anonymous referees for The Journal of Aesthetics and Art Criticism, and audiences at the American Society for Aesthetics Eastern Division meeting in Philadelphia in April 2003 and the Queen's University Philosophy Colloquium in fall 2004. Work on this paper was made possible by a Social Sciences and Humanities Council of Canada postdoctoral fellowship. 